\title{
The Correlation Between STONE Nephrolithometry Score and Hemoglobin Drop in Patients Undergoing Percutaneous Nephrolithotomy
}

\author{
Mohammad Shoaib ${ }^{1}$, Muhibullah Bangash ${ }^{1}$, Basit Salam ${ }^{2}$, M Hammad Ather ${ }^{3}$ \\ 1. Surgery, Aga Khan University Hospital, Karachi, PAK 2. Radiology, Aga Khan University Hospital, Karachi, PAK 3. \\ Urology, Aga Khan University Hospital, Karachi, PAK
}

Corresponding author: M Hammad Ather, hammadather@gmail.com

\section{Abstract \\ Objective}

In this study, we aimed to determine the correlation between the STONE score [(S)ize of the stone, (T)opography or location, degree of $(\mathrm{O})$ bstruction of the urinary system, (N)umber of stones, and (E)valuation of Hounsfield units] and postoperative hemoglobin drop in patients undergoing percutaneous nephrolithotomy (PCNL).

\section{Methods}

This was a prospective observational study and all adult patients aged 18-65 years undergoing unilateral, single-tract PCNL using $26 \mathrm{Ch}$. Amplatz sheath for renal calculi were included. The five variables of the STONE nephrolithometry score were calculated prior to the procedure. The stone-free rates were assessed on imaging at four weeks and complications were graded using the modified Clavien system.

\section{Results}

Of the 142 patients included, $75 \%$ were below 55 years of age. More than half of our patients were diabetic with more than $60 \%$ having a body mass index (BMI) above $25 \mathrm{~kg} / \mathrm{m}^{2}$. The mean STONE score was 7 with $33 \%$ having a high (>9) STONE score. The mean hemoglobin drop was $1.15+0.92 \mathrm{~g} / \mathrm{dL}$ with eight patients (5.63\%) requiring transfusion and one $(0.7 \%)$ requiring angioembolization; one patient required readmission for observation. Complete STONE clearance was achieved with PCNL alone in $78.2 \%$ of the patients. There was a significant correlation of hemoglobin drop with the STONE score, stone size, and preoperative creatinine clearance. Patients with a hemoglobin drop of $>1 \mathrm{~g} / \mathrm{dL}$ had a higher STONE score and mean stone size. The overall complication rate was significantly higher (10.5\%) in patients with a hemoglobin drop of $>1 \mathrm{~g} / \mathrm{dL}$ as compared to those with a hemoglobin drop of $<1 \mathrm{~g} / \mathrm{dL}(2.8 \%)$.

Review began 10/13/2020 Review ended 10/29/2020 Published 11/10/2020

(c) Copyright 2020 Shoaib et al. This is an open access article distributed under the terms of the Creative Commons Attribution License CC-BY 4.0., which permits unrestricted use, distribution, and reproduction in any medium, provided the original author and source are credited.

\section{Conclusion}

Stone complexity as measured by the STONE score correlates with post-PCNL hemoglobin drop, stone clearance, and complication rates. The STONE score may be used for preoperative counseling and to evaluate the potential need for transfusion.

Categories: Urology

Keywords: stone nephrolithometry score, hemoglobin (hemoglobin) drop, percutaneous nephrolithotomy (pcnl)

\section{Introduction}

Percutaneous nephrolithotomy (PCNL) is considered to be the standard treatment for moderate to largesized renal calculi. It is minimally invasive and generally considered a safe and highly effective procedure. However, serious complications, although rare, are encountered in patients with a complex stone burden. Bleeding is common, although often minimal and self-limiting, and it can be life-threatening, requiring transfusions and angioembolization in rare cases. The need for transfusion varies from 1-11\% [1-4], and up to $0.8 \%$ of the patients require angioembolization [5].

The predictors of postoperative bleeding include patient-related factors such as age [3], presence of diabetes mellitus (both type 1 and 2) [4], urinary tract infections [3], and preoperative hemoglobin levels, and stonerelated factors such as large stones, staghorn calculi, stone location, the grade of hydronephrosis, and renal parenchymal thickness [6]. Perioperative factors like multiple access and prolonged surgery time can also influence postoperative bleeding [7]. 
Stone complexity is one of the factors that correlate with postoperative hemoglobin drop. One of the methods of measuring kidney stone complexity is the STONE score. The STONE score is calculated using five variables, abbreviated as the acronym 'S.T.O.N.E.'. These include stone size, tract length (skin-to-stone distance), the degree of obstruction, the number of calyces involved, and stone essence (density) [8]. In their study, Said et al. showed that complete and partial staghorn calculi were associated with a greater blood loss compared to calyx stones [9]. They noted that stone complexity (Guy's Stone Score grades 3 and 4), preoperative creatinine level $(\geqslant 1.4 \mathrm{mg} / \mathrm{dl})$, intraoperative complication (perforation and extravasation), and duration of the operation (>83 minutes) were the most important factors associated with an increased risk of bleeding and transfusion during PCNL. In another study, Syahputra et al. [7] concluded that a larger stone burden or staghorn calculi required a greater amount of unit blood transfused during the PCNL procedure compared to smaller stones.

Stone complexity is a known predictor of postoperative bleeding after PCNL; however, whether the STONE score correlates with postoperative hemoglobin drop is not known. In this study, the correlation between the STONE score and postoperative hemoglobin drop was assessed among patients undergoing PCNL [10]. We hope our findings will help in counseling patients regarding transfusion requirement, hospital stay, and the possible need for embolization.

\section{Materials And Methods}

We performed this non-randomized study at the department of urology of a university hospital. After obtaining institutional review board and ethical review committee approval, all adult patients aged 18-65 years undergoing unilateral, single-tract PCNL using $26 \mathrm{Ch}$. Amplatz sheath for renal calculi were included in the study. We excluded patients undergoing additional procedures such as transurethral resection of the prostate/ureteroscopy (TURP/URS) along with PCNL; patients on anticoagulants, those with skeletal deformity, and those undergoing mini PCNL procedures were also excluded. Surgery was performed in a prone position under general anesthesia and the tract was dilated using serial metallic dilators. Stone fragmentation was done with an ultrasonic probe using EMS ${ }^{\mathrm{TM}}$ or Lithoclast ${ }^{\circledR}$ Master (EMS, Nyon, Switzerland). Smaller residual fragments were cleared using flexible nephroscope and laser. At the end of the procedure, a 12 Fr Foley catheter with the balloon inflated or a 12 Fr Nelaton catheter was placed as a nephrostomy tube at the discretion of the operating surgeon.

A senior radiologist (BS) at the workstation measured the variables such as stone size, tract length, degree and presence of obstruction (hydronephrosis), number of involved calyces, and stone essence (density). Each of the variables was scored according to the predefined system proposed by Okhunov et al. [8] and the STONE nephrolithometry score was calculated.

The sample size of 142 was calculated with an assumed correlation of 0.7 between the STONE score and hemoglobin levels, at a $5 \%$ level of significance, $80 \%$ power, and $10 \%$ inflation. The sample size was calculated by NCSS PASS software version 11 (NCSS, LLC, Kaysville, UT). For data collection, a nonprobability continuous sampling technique was employed.

The primary outcome measure was postoperative hemoglobin drop, which was determined by calculating the difference between preoperative and postoperative hemoglobin measured on the first postoperative day after PCNL. Secondary outcomes were the number of blood transfusions required, the need for angioembolization within 30 days of the procedure, length of hospital stay, and 30-day complications according to modified Clavien grade.

Data were analyzed using SPSS Statistics version 25 (IBM, Armonk, NY). Continuous variables such as age, body mass index (BMI), and the STONE score were described in terms of mean/median and standard deviations. For post-hemoglobin drop, mean difference (preoperative and postoperative hemoglobin) was reported and assessed by paired t-test. Categorical variables such as gender were described in terms of frequencies and percentages. The correlation between the STONE score and postoperative hemoglobin drop was measured by the Pearson correlation/Spearman correlation coefficient as appropriate.

\section{Results}

The basic demographics details are presented in Table 1 . The STONE score and its individual parameters are shown in Table 2. 


\section{Cureus}

\begin{tabular}{|c|c|c|c|}
\hline \multicolumn{2}{|l|}{ Parameters } & Frequency $(\mathrm{N}=142)$ & Mean $( \pm \mathrm{SD} / \%)$ \\
\hline \multicolumn{2}{|l|}{ Age (years) } & & $44.54 \pm 14.3$ \\
\hline \multirow{2}{*}{ Gender } & Male & 87 & $61 \%$ \\
\hline & Female & 55 & $39 \%$ \\
\hline \multirow{2}{*}{ Comorbidities } & DM & 75 & $52.81 \%$ \\
\hline & HTN & 80 & $56.30 \%$ \\
\hline \multicolumn{2}{|c|}{ Hospital stay (days) } & & $2.39 \pm 0.68$ \\
\hline \multirow{5}{*}{$\mathrm{BMI}, \mathrm{kg} / \mathrm{m}^{2}$} & Total & 142 & $27.26 \pm 5.45$ \\
\hline & Underweight & 8 & $5.60 \%$ \\
\hline & Normal (BMI of 18-25) & 44 & $30.90 \%$ \\
\hline & Overweight & 51 & $35.90 \%$ \\
\hline & Obese & 39 & $27.60 \%$ \\
\hline \multicolumn{2}{|l|}{ Smoker } & 25 & $17.60 \%$ \\
\hline \multirow{2}{*}{ Side of surgery } & Left & 79 & $55.20 \%$ \\
\hline & Right & 63 & $44.80 \%$ \\
\hline \multicolumn{2}{|c|}{ Preoperative hemoglobin/hematocrit } & & $13.45 \pm 2.0 / 41.62 \pm 5.47$ \\
\hline \multicolumn{2}{|c|}{ Postoperative hemoglobin/hematocrit } & & $12.30 \pm 1.97 / 37.70 \pm 5.20$ \\
\hline \multicolumn{2}{|c|}{ Preoperative creatinine } & & $1.00 \pm 0.38$ \\
\hline \multicolumn{2}{|c|}{ History of stone surgery } & 48 & $34 \%$ \\
\hline \multicolumn{2}{|c|}{ Postoperative double $\mathrm{J}$ stent } & 33 & $23 \%$ \\
\hline
\end{tabular}

\section{TABLE 1: Demographic details and baseline stone-related and clinical parameters}

SD: standard deviation; DM: diabetes mellitus; HTN: hypertension; BMI: body mass index

\begin{tabular}{|c|c|c|c|}
\hline Variables & Mean \pm SD & Correlation coefficient & P-value \\
\hline Total STONE score & $7.56 \pm 1.64$ & 0.16 & 0.05 \\
\hline Stone size $\left(\mathrm{mm}^{2}\right)$ & $381 \pm 200$ & 0.49 & 0.03 \\
\hline Tract length (mm) & $80.63 \pm 20.40$ & -0.09 & 0.26 \\
\hline Stone density (Hounsfield units) & $910.3 \pm 358.9$ & 0.001 & 0.99 \\
\hline
\end{tabular}

TABLE 2: Correlations of the STONE scores and individual parameters with hemoglobin drop

STONE: size of the stone, topography or location, degree of obstruction of the urinary system, number of stones, and evaluation of Hounsfield units; SD: standard deviation

Of the 142 patients included, $75 \%$ were below 55 years of age. More than half of our patients were diabetic with more than $60 \%$ having a BMI above $25 \mathrm{~kg} / \mathrm{m}^{2}$. Almost all of our patients had normal preoperative hemoglobin ( $60 \%$ with a hemoglobin level of $>13 \mathrm{~g} / \mathrm{dl}$ ). The mean STONE score was 7.12 with $33 \%$ having a high (>9) STONE score. This complexity is attributable to the presence of moderate/severe hydronephrosis and the involvement of more than three calyces in $>50 \%$ of our patients. Overall mean hemoglobin drop was low $(1.15+0.92)$ in our patients with only eight $(5.6 \%)$ requiring transfusion and only one $(0.7 \%)$ requiring angioembolization. One of the patients required readmission and was managed conservatively with bedrest. Complete STONE clearance was achieved with PCNL alone in $78.2 \%$ of the patients. Ancillary 


\section{Cureus}

procedures for the residual stones were needed in 18 patients (12.7\%) (Table 3).

\begin{tabular}{|c|c|c|c|}
\hline \multicolumn{2}{|l|}{ Parameters } & Number of patients & $\pm \mathrm{SD} / \%$ \\
\hline \multicolumn{2}{|c|}{ Mean hemoglobin/hematocrit drop } & & $1.15 \pm 0.92 / 4.14 \pm 3.93$ \\
\hline \multicolumn{2}{|c|}{ Blood transfusion } & 8 & $5.63 \%$ \\
\hline \multicolumn{2}{|c|}{ Hematuria >24 hours } & 4 & $2.92 \%$ \\
\hline \multicolumn{2}{|c|}{ Angioembolization } & 1 & $0.70 \%$ \\
\hline \multicolumn{2}{|l|}{ Complications } & 19 & $13.38 \%$ \\
\hline \multicolumn{2}{|l|}{ Readmission } & 1 & $0.70 \%$ \\
\hline \multicolumn{2}{|l|}{ Fever } & 5 & $3.52 \%$ \\
\hline \multicolumn{2}{|l|}{ Stone clearance } & 111 & $78.16 \%$ \\
\hline \multicolumn{2}{|c|}{ Lost to follow-up } & 8 & $5.63 \%$ \\
\hline \multirow{5}{*}{ Residual stone } & Total & 23 & $16.19 \%$ \\
\hline & Shockwave lithotripsy & 11 & $7.15 \%$ \\
\hline & Ureteroscopy & 6 & $4.22 \%$ \\
\hline & Open stone surgery & 1 & $0.70 \%$ \\
\hline & Observation & 5 & $4.12 \%$ \\
\hline
\end{tabular}

TABLE 3: Outcome parameters including ancillary treatment for residual stones

SD: standard deviation

There was a significant correlation of hemoglobin drop with the total STONE score, stone size, and preoperative creatinine clearance (Table 4). Patients with a hemoglobin drop of $>1 \mathrm{~g} / \mathrm{dl}$ had a higher STONE score and stone size. Overall the complications were higher (10.5\%) in patients with a hemoglobin drop of $>1$ $\mathrm{g} / \mathrm{dl}$ as compared to those with a hemoglobin drop of $<1 \mathrm{~g} / \mathrm{dL}(2.8 \%)$ (Table 5). 


\section{Cureus}

\begin{tabular}{|c|c|c|c|}
\hline & & Number of patients & $\pm \mathrm{SD} / \%$ \\
\hline \multirow{4}{*}{ STONE score } & Mean & & $7.56 \pm 1.64$ \\
\hline & Low (4-5) & 19 & $13.38 \%$ \\
\hline & Moderate (6-8) & 75 & $52.82 \%$ \\
\hline & High (>9) & 48 & $33.80 \%$ \\
\hline \multirow{4}{*}{ Stone size $\left(\mathrm{mm}^{2}\right)$} & Mean & & $380.97 \pm 199.82$ \\
\hline & $0-399$ & 91 & $64.08 \%$ \\
\hline & 400-799 & 46 & $32.39 \%$ \\
\hline & $800-1,599$ & 5 & $3.53 \%$ \\
\hline \multirow{3}{*}{ Tract length $(\mathrm{mm})$} & Mean & & $80.63 \pm 20.40$ \\
\hline & $<100$ & 115 & $81 \%$ \\
\hline & $>100$ & 27 & $19 \%$ \\
\hline \multirow{2}{*}{ Obstruction } & No/mild & 57 & $40.14 \%$ \\
\hline & Moderate/severe & 85 & $59.96 \%$ \\
\hline \multirow{3}{*}{ Calyces involved (n) } & $1-2$ & 61 & $42.15 \%$ \\
\hline & 3 & 36 & $25.35 \%$ \\
\hline & Staghorn & 45 & $31.70 \%$ \\
\hline \multirow{3}{*}{ Stone density (Hounsfield units) } & Mean & & $910.28 \pm 358.86$ \\
\hline & $<950$ & 67 & $47.18 \%$ \\
\hline & 950 & 75 & 2.82 \\
\hline
\end{tabular}

TABLE 4: Stone-related parameters, calyces involved, and degree of obstruction 


\section{Cureus}

\begin{tabular}{|c|c|c|c|}
\hline & Hemoglobin drop of $<1$ & Hemoglobin drop of $>1$ & P-value \\
\hline Female (n) & 24 & 31 & 0.62 \\
\hline Males (n) & 43 & 44 & 0.7 \\
\hline Age (years) & 46.21 & 43.04 & 0.19 \\
\hline BMI & 27.61 & 26.94 & 0.46 \\
\hline Preoperative hemoglobin (gm/dl) & 13.19 & 13.7 & 0.14 \\
\hline Postoperative Hemoglobin (gm/dl) & 12.73 & 11.93 & 0.02 \\
\hline Preoperative creatinine (mean, mg/dl) & 1.04 & 0.97 & 0.28 \\
\hline Nondiabetic (n) & 29 & 38 & 0.48 \\
\hline Diabetes present (n) & 38 & 37 & 0.48 \\
\hline Nonhypertensive (n) & 34 & 46 & 0.27 \\
\hline Hypertensive (n) & 33 & 29 & 0.27 \\
\hline Non-smoker (n); smoker (n) & $55 ; 12$ & $57 ; 18$ & 0.5 \\
\hline Left side $(\mathrm{n})$ & 39 & 40 & 0.68 \\
\hline Right side (n) & 39 & 40 & 0.68 \\
\hline STONE score (mean) & 7.12 & 8.03 & 0.04 \\
\hline Stone size $\left(\mathrm{mm}^{2}\right)$ & 219.81 & 468.71 & 0.03 \\
\hline Tract length (mm) & 81 & 79.45 & 0 \\
\hline
\end{tabular}

TABLE 5: Comparison of the groups regarding various outcome parameters in patients who had < or $>1 \mathrm{gm} / \mathrm{dl}$ hemoglobin drop

BMI: body mass index

\section{Discussion}

Hematuria is one of the most dreaded complications of PCNL. Mostly it is mild and self-limiting, however, occasionally it could be life-threatening. Ultrasound-guided access [10], miniaturization of the instruments [11], use of the balloon catheter nephrostomy tube [12], and tubeless PCNL with the use of tract sealant [13] are some of the ways described to minimize bleeding complications. Various patient and stone-related factors have also been studied to predict PCNL complications including previous interventions [14]. Various nephrolithometry scoring systems have been described to objectively quantify the parameters. In this study, we have attempted to correlate one of the most commonly used scoring systems, i.e., the STONE score, to predict bleeding complications of PCNL.

The correlation of the STONE score with postoperative hemoglobin drop has not been previously assessed in contemporary literature. Most of the previous studies have correlated the STONE score with estimated blood loss (EBL), which is often difficult to quantify. However, hemoglobin drop is a more objective way of assessing blood loss as compared to EBL.

Our study showed that there is a significant correlation between the STONE score and hemoglobin drop $(\mathrm{p}=0.05)$. Okhunov et al. [8] noted that the STONE score has a significant association with EBL $(\mathrm{p}=0.005)$ during PCNL. Another study by Yarimoglu et al. [15] showed no significant association between the STONE score and EBL. The mean hemoglobin drop was $1.15 \pm 0.92$ in our study, which is similar to a recent study by Jamil et al. [12] comparing Foley and Nelaton ${ }^{\mathrm{TM}}$ catheter nephrostomy tubes. However, they noted no significant difference in the mean hemoglobin drop in the two groups with balloon versus non-balloon catheter nephrostomy respectively $(1.08 \pm 0.7$ and $1.14 \pm 0.69)$. Said et al. [9] noted a hemoglobin drop of 1.5 $\pm 1 \mathrm{~g} / \mathrm{dl}$ in the treatment of staghorn stones, which is comparatively higher than our hemoglobin drop; similarly, they noted a $14 \%$ blood transfusion rate as compared to only $5.63 \%$ in our study. Indication of a complex stone burden may be associated with greater blood loss. Hemoglobin drop of $>1 \mathrm{~g} / \mathrm{dl}$ was noted in patients with a STONE score of more than 8.03 as compared to a STONE score of less than $7.12(\mathrm{p}=0.04)$. Most patients with complications (15 out of 19), had a hemoglobin drop of $>1 \mathrm{~g} / \mathrm{dl}$ ( $\mathrm{p} 0.04$ ), which further 
implies that the increase in stone complexity shown by the STONE score is correlated with both the complications and blood loss. Our results showed that hemoglobin drop is also associated with stone size $(p=0.03)$, which is similar to Okhunov et al.'s [8] study findings ( $p=0.047)$. Other individual components of the STONE score like skin-to-stone distance, stone density, and the presence of hydronephrosis did not show any significant association with hemoglobin drop in our study. This result is also similar to the findings of Okhunov et al. [8].

Another noteworthy observation in the current work is that a postoperative hemoglobin drop of $>1$ $\mathrm{g} / \mathrm{dl}$ correlated with higher preoperative hemoglobin $(13.7 \mathrm{~g} / \mathrm{dl})$ and lower preoperative creatinine $(0.97$ $\mathrm{mg} / \mathrm{dl}$ ). Hemoglobin drop was $1.76 \mathrm{~g} / \mathrm{dl}$ with mean preoperative hemoglobin of $13.7 \mathrm{~g} / \mathrm{dl}$ as compared to a drop of only $0.46 \mathrm{~g} / \mathrm{dl}$ with mean preoperative hemoglobin of $13.2 \mathrm{~g} / \mathrm{dl}$. This can be an incidental finding with a statistical significance and needs to be analyzed further in order to understand its clinical significance.

In our study, the mean hemoglobin drop was $1.15 \pm 0.92$, and the mean hematocrit drop was $4.14 \pm 3.93$. A previous study done by Zehri et al. [16] at the same institute showed a mean hemoglobin drop of $1.68 \pm 1.3$ $\mathrm{gm} / \mathrm{dl}$, which indicates that the overall hemoglobin drop has decreased with time. Total blood transfusion in our current study has decreased to $5.63 \%(\mathrm{n}=8)$ and only one patient $(0.70 \%)$ required angioembolization. Zehri et al. [16] reported a higher transfusion rate of $14.2 \%(n=33)$ with one of the patients $(0.43 \%)$ requiring angioembolization [16].

At the authors' institution, all PCNLs are performed in the prone position and under general anesthesia. We predominantly use an ultrasonic probe for fragmentation or Lithoclast ${ }^{\circledR}$ Master with both ultrasound and pneumatic lithotripsy. The laser is not used for standard PCNL, except in a situation where a flexible nephroscope is used to overcome the difficulty to reach the caliceal fragment. Although regional and local anesthesia is also described for performing PCNL, in the current work, only general anesthesia was used. This, in our view, does not cause any limitations but limits the use of PCNL in patients who are ineligible for general anesthesia. However, it provides standardization in assessing outcomes in the current study.

The major strength of this study is that it is the first in-depth study correlating the STONE score with hemoglobin drop. We have included all types of patients, ranging from those with simple kidney stones to those with complicated ones. The major limitation of this study was that it was a monocentric study, with a relatively small sample size and short-term follow-ups. However, we believe that the results of this study will help in preoperative counseling of patients about the need for transfusions, hospital stay, and complications.

\section{Conclusions}

Based on our findings, stone complexity as measured by the STONE score correlates with post-PCNL hemoglobin drop, stone clearance, and complications. Therefore, the STONE score can be used for preoperative counseling and to determine potential blood requirements.

\section{Additional Information \\ Disclosures}

Human subjects: Consent was obtained by all participants in this study. Ethics Review Committee, Aga Khan University issued approval 2019-0844-2643. This study was approved by the Ethics Review Committee of the Aga Khan University. Animal subjects: All authors have confirmed that this study did not involve animal subjects or tissue. Conflicts of interest: In compliance with the ICMJE uniform disclosure form, all authors declare the following: Payment/services info: All authors have declared that no financial support was received from any organization for the submitted work. Financial relationships: All authors have declared that they have no financial relationships at present or within the previous three years with any organizations that might have an interest in the submitted work. Other relationships: All authors have declared that there are no other relationships or activities that could appear to have influenced the submitted work.

\section{References}

1. Farhan M, Nazim SM, Salam B, Ather MH: Prospective evaluation of outcome of percutaneous nephrolithotomy using the 'STONE' nephrolithometry score: a single-centre experience. Arab J Urol. 2015, 13:264-9. 10.1016/j.aju.2015.07.006

2. Kukreja R, Desai M, Patel S, Bapat S, Desai M: Factors affecting blood loss during percutaneous nephrolithotomy: prospective study. J Endourol. 2004, 18:715-22. 10.1089/end.2004.18.715

3. Keoghane SR, Cetti RJ, Rogers AE, Walmsley BH: Blood transfusion, embolisation and nephrectomy after percutaneous nephrolithotomy (PCNL). BJU Int. 2013, 111:628-32. 10.1111/j.1464-410X.2012.11394.x

4. Akman T, Binbay M, Sari E, et al.: Factors affecting bleeding during percutaneous nephrolithotomy: single surgeon experience. J Endourol. 2011, 25:327-33. 10.1089/end.2010.0302

5. Turna B, Nazli O, Demiryoguran S, Mammadov R, Cal C: Percutaneous nephrolithotomy: variables that influence hemorrhage. Urology. 2007, 69:603-7. 10.1016/j.urology.2006.12.021

6. Kyriazis I, Panagopoulos V, Kallidonis P, Özsoy M, Vasilas M, Liatsikos E: Complications in percutaneous 


\section{Cureus}

nephrolithotomy. World J Urol. 2015, 33:1069-77. 10.1007/s00345-014-1400-8

7. Syahputra FA, Birowo P, Rasyid N, Matondang FA, Noviandrini E, Huseini MH: Blood loss predictive factors and transfusion practice during percutaneous nephrolithotomy of kidney stones: a prospective study. F1000Res. 2016, 5:1550. 10.12688/f1000research.8993.1

8. Okhunov Z, Friedlander JI, George AK, et al.: S.T.O.N.E. nephrolithometry: novel surgical classification system for kidney calculi. Urology. 2013, 81:1154-9. 10.1016/j.urology.2012.10.083

9. Said S, Aghaways I, Fryad G: Review of factors affecting total blood loss and need for blood transfusion in a series of patient undergoing unilateral percutaneous nephrolithotomy. Urol Nephrol Open Access J. 2016, 3:00108. 10.15406/unoaj.2016.03.00108

10. Yang YH, Wen YC, Chen KC, Chen C: Ultrasound-guided versus fluoroscopy-guided percutaneous nephrolithotomy: a systematic review and meta-analysis. World J Urol. 2019, 37:777-88. 10.1007/s00345018-2443-z

11. Lahme S: Miniaturisation of PCNL. Urolithiasis. 2018, 46:99-106. 10.1007/s00240-017-1029-3

12. Jamil S, Ather MH: The impact of post PCNL tube type on blood loss and postoperative pain . Pak J Med Sci. 2020, 36:402-6. 10.12669/pjms.36.3.1558

13. Mouracade P, Spie R, Lang H, Jacqmin D, Saussine C: Tubeless percutaneous nephrolithotomy: what about replacing the Double-J stent with a ureteral catheter?. J Endourol. 2008, 22:273-5. 10.1089/end.2007.0162

14. Yesil S, Ozturk U, Goktug HN, Tuygun C, Nalbant I, Imamoglu MA: Previous open renal surgery increased vascular complications in percutaneous nephrolithotomy (PCNL) compared with primary and secondary PCNL and extracorporeal shock wave lithotripsy patients: a retrospective study. Urol Int. 2013, 91:331-4. 10.1159/000351968

15. Yarimoglu S, Polat S, Bozkurt IH, Yonguc T, Aydogdu O, Aydın E, Degirmenci T: Comparison of S.T.O.N.E and CROES nephrolithometry scoring systems for predicting stone-free status and complication rates after percutaneous nephrolithotomy: a single center study with 262 cases. Urolithiasis. 2017, 45:489-94. 10.1007/s00240-016-0935-0

16. Zehri AA, Biyabani SR, Siddiqui KM, Memon A: Triggers of blood transfusion in percutaneous nephrolithotomy. J Coll Physicians Surg Pak. 2011, 21:138-41. 